Review Article

doi: 10.29052/IJEHSR.v5.i3.2017.33-36

Maternal Obesity and Gestational Diabetes Mellitus: The

Pathological Programming. Hina Hazrat ${ }^{1 *}$ \& Sadaf Ahmed ${ }^{1,2}$

${ }^{1}$ Department of Physiology, University of Karachi, Pakistan.

${ }^{2}$ Advance Educational Institute and Research Centre, Karachi, Pakistan.

*Corresponding Author Email ID: hhk.hina@gmail.com

Received 11/12/17; Accepted 20/12/17; First Published 30/12/17

Abstract

Background: Onset or development of glucose intolerance during the period of gestation is termed as gestational diabetes mellitus. Maternal obesity along with GDM is found associated with development of adverse maternal and fetal health outcomes.

Method: Researches with a focus on maternal obesity and gestational diabetes mellitus were included in this study.

Results: Elevated state of maternal body mass index is found to raise the inflammatory condition in GDM, which may play role in impacting downstream metabolic processes giving rise to manifestation of glucose dysregulation and condition of insulin resistance. Obesity in gestation, is related to the alterations in metabolic status comprising dyslipidemia, hyperinsulinemia, impaired endothelial functioning, and increased blood pressure.

Conclusion: Previous studies have provided findings associating the risk of GDM development with the state of BMI, which emphasizes the need to explore mechanisms governing obesity mediated GDM development and related maternal and fetal health complications during gestation. In view of existing literature, weight management and engagement in physical activities should be encouraged among women during and after the period of gestation.

\title{
Keywords
}

Maternal Obesity, Body Mass Index, Gestational Diabetes Mellitus, Physical Activity.

Glucose intolerance with an onset or first recognition during gestation is termed as gestational diabetes mellitus $(\mathrm{GDM}){ }^{1}$. The insulin resistance in GDM is found associated with impaired insulin receptor auto-phosphorylation resulting from its reduced protein expression ${ }^{2}$. GDM is considered as a risk factor for various adverse health outcomes ${ }^{3}$, including the future development of type 2 diabetes ${ }^{2,4-6}$ and metabolic syndrome ${ }^{4}$. Maternal obesity coupled with GDM is found to influence perinatal outcomes ${ }^{7}$. Moreover, previous findings have indicated obesity and diabetes as two independent risk factors for multiple poor outcomes of pregnancy ${ }^{8}$.
The related consequences of maternal glucose intolerance is found to impact fetal health outcomes ${ }^{9,10}$ including increased risk of early obesity, development of type 2 diabetes and metabolic syndrome ${ }^{4}$. Obesity coupled with GDM is found associated with pathogenesis of offspring congenital anomalies, including defects at craniofacial and musculoskeletal level ${ }^{11}$ and large for gestational age risk ${ }^{12}$. Furthermore, obesity and GDM are found to elevate placental leptin methylation which may represent one of the possible ways through which placental epigenetic changes influence fetal health conditions ${ }^{13}$. Obesity and GDM may contribute in intrauterine reprogramming of 
offspring obesity ${ }^{14}$, vascular disease ${ }^{15}$, macrosomic neonates ${ }^{16}$, cesarean delivery ${ }^{16}$, and other fetal health complications ${ }^{13}$.

Increased maternal weight is reported to be related with a higher risk of $\mathrm{GDM}^{17}$. Elevated maternal BMI status is found to mediate inflammatory responses during $\mathrm{GDM}^{18,}{ }^{19}$, which may play its part in altering the maternal normal regulation of insulin signaling and the glucose transport processes $^{19}$. Maternal obesity and GDM may play role in indirect programming of fetus for diseases by impacting placental functioning during period of maternal inflammatory milieu; the placenta is found to adjust to this environment of inflammation and participate as the target part and producer region of inflammatory mediators ${ }^{20 .}$ Obesity in gestation is found to alter metabolic status comprising dyslipidemia which is reported to be manifested approximately 10 weeks before GDM diagnosis during period of late second trimester ${ }^{21}$. Furthermore, obesity in pregnancy as in obese women (nonpregnant), is found related to altered condition of hyperinsulinemia, dyslipidemia, compromised endothelial functioning, and elevated blood pressure and enhanced inflammatory state $^{15}$. These impaired conditions may underpin the mechanisms driving complications in obese women with $\mathrm{GDM}^{15}$.

The risk of GDM development is found associated positively with the state of BMI prior gestation $^{22}$. In obese women, the GDM risk is found to escalate 1.3-3.8 times as compared to women having normal $\mathrm{BMI}^{23}$. Previous study presented findings indicating that reduced levels of plasma adiponectin is linked to GDM, exhibiting insight into state of insulin resistance and inflammation in $\mathrm{GDM}^{24}$. Obese women with GDM have shown elevated insulin response but reduced sensitivity of insulin and also reduced hepatic glucose formation during period of insulin infusion with state of progressing gestation $^{25}$. These abnormal conditions at metabolic level may provide insight into type 2 diabetes development in women with GDM later in life ${ }^{25}$. The diagnosis of GDM coupled with altered $\beta$-cell functioning and obese BMI status are found associated with future diabetes development ${ }^{26}$. Maternal serum C-reactive protein levels are found related with pre-pregnancy obese BMI status and not to GDM, depicting potential model for obesity driven inflammation at systemic level, which may further impact downstream metabolic pathways contributing toward manifestation of glucose dysregulation and insulin resistance state ${ }^{19}$.

In view of existing literature, which associate GDM risk with BMI, weight management and physical activity should be encouraged among women during the childbearing period and the time beyond ${ }^{22}$, 27-32.

\section{Conflicts of interests}

None.

\section{Acknowledgment}

None.

\section{Funding}

None.

\section{References}

1. Oats JJ. Fourth International WorkshopConference on Gestational Diabetes Mellitus: Overview and commentary on first session. Diabetes care. 1998;21:B58.

2. Friedman JE, Ishizuka T, Shao J, Huston L, Highman T, Catalano P. Impaired glucose transport and insulin receptor 
tyrosine phosphorylation in skeletal muscle from obese women with gestational diabetes. Diabetes. 1999;48(9):1807-14.

3. Ovesen PG, Jensen DM, Damm P, Rasmussen S, Kesmodel US. Maternal and neonatal outcomes in pregnancies complicated by gestational diabetes. A nation-wide study. The Journal of Maternal-Fetal \& Neonatal Medicine. 2015;28(14):1720-4.

4. Yogev Y, Visser GH, editors. Obesity, gestational diabetes and pregnancy outcome. Seminars in Fetal and Neonatal Medicine; 2009: Elsevier.

5. Bellamy L, Casas J-P, Hingorani AD, Williams D. Type 2 diabetes mellitus after gestational diabetes: a systematic review and meta-analysis. The Lancet. 2009;373(9677):1773-9.

6. Kim C, Newton KM, Knopp RH. Gestational diabetes and the incidence of type 2 diabetes. Diabetes care. 2002;25(10):1862-8.

7. Yogev Y, Langer O. Pregnancy outcome in obese and morbidly obese gestational diabetic women. European Journal of Obstetrics \& Gynecology and Reproductive Biology. 2008;137(1):216.

8. Rosenberg TJ, Garbers S, Lipkind $\mathrm{H}$, Chiasson MA. Maternal obesity and diabetes as risk factors for adverse pregnancy outcomes: differences among $4 \mathrm{racial} / \mathrm{ethnic}$ groups. American journal of public health. 2005;95(9):1545-51.

9. Casey BM, Lucas MJ, McIntire DD, Leveno KJ. Pregnancy outcomes in women with gestational diabetes compared with the general obstetric population. Obstetrics \& Gynecology. 1997;90(6):869-73.

10. Alberico S, Montico M, Barresi V, Monasta L, Businelli C, Soini V, et al. The role of gestational diabetes, pre- pregnancy body mass index and gestational weight gain on the risk of newborn macrosomia: results from a prospective multicentre study. BMC pregnancy and childbirth. 2014;14(1):23.

11. Moore LL, Singer MR, Bradlee ML, Rothman KJ, Milunsky A. A prospective study of the risk of congenital defects associated with maternal obesity and diabetes mellitus. Epidemiology. 2000;11(6):689-94.

12. Kim SY, Sharma AJ, Sappenfield W, Wilson HG, Salihu HM. Association of maternal body mass index, excessive weight gain, and gestational diabetes mellitus with large-for-gestational-age births. Obstetrics and gynecology. 2014;123(4):737.

13. Lesseur C, Armstrong DA, Paquette AG, Li Z, Padbury JF, Marsit CJ. Maternal obesity and gestational diabetes are associated with placental leptin DNA methylation. American journal of obstetrics and gynecology. 2014;211(6):654. e1-. e9.

14. Gillman MW, Rifas-Shiman S, Berkey CS, Field AE, Colditz GA. Maternal gestational diabetes, birth weight, and adolescent obesity. Pediatrics. 2003;111(3):e221-e6.

15. Ramsay JE, Ferrell WR, Crawford L, Wallace AM, Greer IA, Sattar N. Maternal obesity is associated with dysregulation of metabolic, vascular, and inflammatory pathways. The Journal of Clinical Endocrinology \& Metabolism. 2002;87(9):4231-7.

16. Cheng YW, Chung JH, Kurbisch-Block I, Inturrisi M, Shafer S, Caughey AB. Gestational weight gain and gestational diabetes mellitus: perinatal outcomes. Obstetrics \& Gynecology. 2008;112(5):1015-22.

17. Chu SY, Callaghan WM, Kim SY, Schmid CH, Lau J, England LJ, et al. 
Maternal obesity and risk of gestational diabetes mellitus. Diabetes care. 2007;30(8):2070-6.

18. Wolf M, Sandler L, Hsu K, VossenSmirnakis K, Ecker JL, Thadhani R. First-trimester C-reactive protein and subsequent gestational diabetes. Diabetes care. 2003;26(3):819-24.

19. Retnakaran R, Hanley AJ, Raif N, Connelly PW, Sermer M, Zinman B. Creactive protein and gestational diabetes: the central role of maternal obesity. The Journal of Clinical Endocrinology \& Metabolism. 2003;88(8):3507-12.

20. Pantham P, Aye ILH, Powell TL. Inflammation in maternal obesity and gestational diabetes mellitus. Placenta. 2015;36(7):709-15.

21. White SL, Pasupathy D, Sattar N, Nelson SM, Lawlor DA, Briley AL, et al. Metabolic profiling of gestational diabetes in obese women during pregnancy. Diabetologia. 2017;60(10):1903-12.

22. Torloni M, Betrán A, Horta B, Nakamura M, Atallah A, Moron A, et al. Prepregnancy BMI and the risk of gestational diabetes: a systematic review of the literature with meta-analysis. Obesity Reviews. 2009;10(2):194-203.

23. Kim SY, Sappenfield W, Sharma AJ, Wilson HG, Bish CL, Salihu HM, et al. Racial/ethnic differences in the prevalence of gestational diabetes mellitus and maternal overweight and obesity, by Nativity, Florida, 2004-2007. Obesity. 2013;21(1).

24. Ranheim T, Haugen F, Staff AC, Braekke K, Harsem NK, Drevon CA. Adiponectin is reduced in gestational diabetes mellitus in normal weight women. Acta obstetricia et gynecologica Scandinavica. 2004;83(4):341-7.

25. Catalano PM, Huston L, Amini SB, Kalhan SC. Longitudinal changes in glucose metabolism during pregnancy in obese women with normal glucose tolerance and gestational diabetes mellitus. American journal of obstetrics and gynecology. 1999;180(4):903-16.

26. Metzger BE, Cho NH, Roston SM, Radvany R. Prepregnancy weight and antepartum insulin secretion predict glucose tolerance five years after gestational diabetes mellitus. Diabetes care. 1993;16(12):1598-605.

27. Kim SY, England L, Wilson HG, Bish C, Satten GA, Dietz P. Percentage of gestational diabetes mellitus attributable to overweight and obesity. American Journal of Public Health. 2010;100(6):1047-52.

28. Baci Y, Üstüner I, Keskin HL, Ersoy R, Avşar AF. Effect of maternal obesity and weight gain on gestational diabetes mellitus. Gynecological Endocrinology. 2013;29(2):133-6.

29. Langer O, Yogev Y, Most O, Xenakis EM. Gestational diabetes: the consequences of not treating. American journal of obstetrics and gynecology. 2005;192(4):989-97.

30. Butte NF. Carbohydrate and lipid metabolism in pregnancy: normal compared with gestational diabetes mellitus. The American journal of clinical nutrition. 2000;71(5):1256s-61s.

31. Tobias DK, Zhang C, Van Dam RM, Bowers K, Hu FB. Physical activity before and during pregnancy and risk of gestational diabetes mellitus. Diabetes care. 2011;34(1):223-9.

32. Dempsey JC, Sorensen TK, Williams MA, Lee I-M, Miller RS, Dashow EE, et al. Prospective study of gestational diabetes mellitus risk in relation to maternal recreational physical activity before and during pregnancy. American journal of epidemiology. 2004;159(7):663-70. 